\title{
Clinical Characteristics of and Cancer Incidence in Children Evaluated for Lymphadenoapthy Referred to Pediatric Oncology Clinics
}

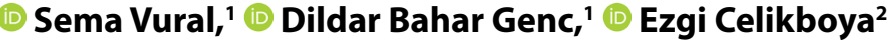 \\ 'Deparment of Pediatric Oncology, Sisli Hamidiye Etfal Training and Research Hospital, Istanbul, Turkey \\ ${ }^{2}$ Department of Pediatrics, Sisli Hamidiye Etfal Training and Research Hospital, Istanbul, Turkey
}

\begin{abstract}
Objectives: In our study, we aimed to investigate the clinical characteristics and cancer frequency in patients referred to our pediatric oncology outpatient clinic for lymphadenopathy.

Methods: The charts of patients admitted to our pediatric oncology outpatient clinics for lymphadenopathy between January 2014, and December 2016 were retrospectively reviewed in this study. Age, gender, duration of complaints, previous therapies, systemic signs and symptoms, lymph node characteristics and laboratory findings were recorded. The frequency of malignancy was calculated. Results: One hundred thirty-four patients (34 girls) with a median age of six years (range four months-17 years) were included in our study. The majority of the patients (98\%) had localized lymphadenopathy and the head and neck region was the most common site of involvement (87\%). The median long-axis diameter of lymph nodes ranged between $0.5 \mathrm{~cm}$ and $5 \mathrm{~cm}$ (median $2 \mathrm{~cm}$ ) by physical examination. Twenty-one patients (15.6\%) had lymph node biopsy. Four patients had ruptured epidermal cyst, lymphangioma, pilomatricoma and ectopic thymus. Of the other biopsies, nine patients were diagnosed with reactive LAP, four with lymphadenitis, and four with Hodgkin's disease. The lymphoma patients had lymph node size greater than $2.5 \mathrm{~cm}$ and the duration of lymphadenopathy was longer than four weeks. Three out of four patients had systemic clinical findings accompanying lymph node enlargement.

Conclusion: Three percent of the patients with lymphadenopathy who were referred for suspected malignancy received a cancer diagnosis. This rate, which is too low for a reference center, suggested that the patients might be referred to the pediatric oncology outpatient clinic without a thorough evaluation in primary health care.

Keywords: cancer; children; lymphadenopathy.

Please cite this article as "Vural S, Genc DB, Celikboya E. Clinical Characteristics of and Cancer Incidence in Children Evaluated for Lymphadenoapthy Referred to Pediatric Oncology Clinics. Med Bull Sisli Etfal Hosp 2020;54(2):222-226".
\end{abstract}

ymphadenopathy is a common clinical finding in child-

-hood. The lymph node size above the expected limits and/or disruption of its structure is called LAP. Although it varies according to the region where the lymph node is located, lymph nodes that are generally greater than $1-1.5 \mathrm{~cm}$, and in some resources larger than $2.5 \mathrm{~cm}$ and/ or deformed structure are considered pathological. LAP is most often seen in response to regional or systemic acute infections and has a good course. Severe diseases, such as chronic infections, rheumatological diseases and rarely childhood cancers, can be included in its etiology. The frequency of cancer among patients who are followed up due to growth in lymph nodes varies according to the centers. In primary care centers, the proportion of patients diag-

Address for correspondence: Sema Vural, MD. Sisli Hamidiye Etfal Egitim ve Arastirma Hastanesi, Cocuk Onkolojisi Bolumu, Istanbul, Turkey Phone: +90 5325020430 E-mail: sdvural@yahoo.com

Submitted Date: June 04, 2018 Accepted Date: July 16, 2018 Available Online Date: October 10, 2019

${ }^{\circ}$ Copyright 2020 by The Medical Bulletin of Sisli Etfal Hospital - Available online at www.sislietfaltip.org

OPEN ACCESS This is an open access article under the CC BY-NC license (http://creativecommons.org/licenses/by-nc/4.0/). 
nosed with cancer in all age groups generally does not exceed one percent.

The likelihood of malignancy is much lower in children, especially in acute conditions. ${ }^{[1-5]}$ Referral of patients without adequate evaluation of cancer risk reduces the rate of cancer in reference centers. Directing patients with lymph node enlargement to outpatient clinics of pediatric oncology without investigating and monitoring other causes in its etiology may cause panic in patient and family and an increase in the burden of oncology outpatient clinics. In our study, we planned to determine the clinical and laboratory features, rates of biopsy procedures and cancer diagnosis of patients who were sent to our oncology outpatient clinics with the diagnosis of the LAP.

\section{Methods}

Patients who were referred to our pediatric oncology outpatient clinic with the diagnosis of the LAP between January 2014 and December 2016 formed the study group. The patients were determined according to the diagnostic codes of ICD were examined retrospectively. As diagnostic codes, R59 (enlarged lymph nodes), L04 (acute lymphadenitis), 188 (lymphadenitis other) were chosen. Data were obtained from the files created in the polyclinic computer system of the patients determined according to these codes. Information about the center that sent these patients means of transportation, age, and gender of the patients' duration of their complaints, presence of systemic signs and symptoms, location and structure of the lymph node; the results of the examinations performed in the center and hospital where the patient was first applied, and antibiotherapy administered (if any) were recorded. The proportion of patients who needed a biopsy and the frequency of malignancy were calculated, and the features that might be related to malignancy were investigated.

\section{Results}

A total of 134 patients who came to our clinic with the diagnosis of LAP formed the study group. Eighty percent of the patients with a male/female ratio of 32/102 and a median age of six years (4 months-17 years), were sent from pediatric polyclinics of other centers through the Central Physician Appointment System (MHRS), while 20\% them were sent from the pediatric, pediatric surgery or ENT (ear nose, and throat) polyclinics of our hospitals for consultation. Since the patients who were referred via MHRS were not given an epicrisis about the indication for referral to oncology, all information about the examinations and treatments was obtained from the family and the reports of examination results they kept with them. Peripheral lymph nodes were noticed by the family in $86 \%$, and by the physicians in $14 \%$ of the patients to whom they were applied with another complaint.

In patients sent with the diagnosis of mesenteric LAP, lymph node size was determined on the ultrasonography (US) requested with the indication of abdominal pain. The median time elapsed between the first application to a physician and the referral to oncology in the whole group was 13 days and ranged from one day to four years (Table 1).

Our patients had upper respiratory tract infection (URT:60\%), typical adenoid face and/or allergic rhinitis (22\%). Dental caries were detected in $12 \%$ and skin infection in $3 \%$ of all cases, while $7 \%$ of them complained of abdominal pain. One patient was in the active period of chickenpox infection.

When the examinations performed before referrals to our outpatient clinic were reviewed, it was seen that the most requested examination was ultrasonography (US) for the enlarging lymph node. Information about the size of the lymph node was given in $62 \%$ of US reports, and findings of fatty hilus, bleeding, resistance and echogenicity that could be used in differential diagnosis were not specified. The lymph node sizes reported in the US reports of $90 \%$ of the patients were larger than patients measured during the examination. The rates of other examinations performed are shown in Table 2. There was microcytic anemia in four cases and positive EBV IGM in two of the blood tests. None of the patients were referred to the dentist or allergy outpatient clinic before referral to oncology.

Ninety-eight percent of the lymph nodes were regional and most commonly located in the cervical location. Their

Table 1. Characteristics of the lymph nodes

\begin{tabular}{lc}
\hline Characteristics & $\mathbf{n , ~ ( \% )}$ \\
\hline Locations & $\mathbf{3}(\mathbf{2})$ \\
Common & $\mathbf{1 3 1}(\mathbf{9 8 )}$ \\
$\quad$ Regional & 108 \\
$\quad$ Cervical & 4 \\
$\quad$ Submandibular & 3 \\
$\quad$ Suboccipital & 2 \\
$\quad$ Supraclavicular & 4 \\
$\quad$ Axillary & 3 \\
$\quad$ Inguinal & 7 \\
$\quad$ Mesenteric & \\
Dimensions, $0.5-5$ cm (median 2 cm) & $33(24.6)$ \\
$<1 \mathrm{~cm}$ & $92(68.7)$ \\
$1-2.5 \mathrm{~cm}$ & $9(6.7)$ \\
$>=2.5 \mathrm{~cm}$ & \\
Duration, 1 day- 4 years (median 13 days) & $82(61)$ \\
$<2$ weeks & $16(12)$ \\
\hline 1 year &
\end{tabular}


Table 2. Tests and examinations requested from the patients

\begin{tabular}{lc}
\hline Tests & $\mathbf{n , ~ ( \% )}$ \\
\hline Complete blood count & $94(70)$ \\
Peripheral smear & $11(8)$ \\
Biochemical & $51(38)$ \\
Viral tests & $28(21)$ \\
Chest X-ray & $2317)$ \\
US of LAP & $134(100)$ \\
\hline
\end{tabular}

dimensions were found between $0.5-5 \mathrm{~cm}$ (median $2 \mathrm{~cm}$ ) during physical examination (Table 1). The lymph nodes had normal histology in $24.6 \%$ of the cases and they measured $1 \mathrm{~cm}$ or less in diameter. Since there were no serious accompanying systemic signs and symptoms, lymph nodes were not evaluated pathologically and removed from follow-up. One patient in the group had hepatosplenomegaly and two patients had splenomegaly. Organomegalies exceeded normal limits at most $2 \mathrm{~cm}$. They had soft consistencies and regressed during follow-up; these organomegalies were thought to be due to infection.

The antibiotherapy was initiated in $90 \%$ of the patients, and treatment was continued in patients still taking antibiotics. Among other patients, any treatment was not administered to any patient other than a patient with a dental abscess, who was considered to receive undertreatment.

A biopsy was performed in 21 (15.6\%) of the cases. The pathological examination results are summarized in Table 3. The

Table 3. Distribution of the diagnoses among biopsized patients

\begin{tabular}{lc}
\hline Results of the histopathology reports & $\mathbf{n}$ \\
\hline Reactive changes & $\mathbf{9}$ \\
Lymphadenitis & $\mathbf{4}$ \\
$\quad$ Nonspecific & 1 \\
Granulomatous & 3 \\
Hodgkin lymphoma & $\mathbf{4}$ \\
Indications unrelated to lymph nodes & $\mathbf{4}$ \\
Epidermal cyst & 1 \\
Lymphangioma & 1 \\
Pilomatrchoma & 1 \\
Ectopic thymus & 1 \\
Total & 21 \\
\hline
\end{tabular}

cancer detection rate was $19 \%$ among biopsized patients and $3 \%$ in the whole group. In patients diagnosed with Hodgkin lymphoma, the LAP size was greater than $2.5 \mathrm{~cm}$, and the LAP was present for longer than four weeks. In addition, three of them had accompanying systemic findings (Table 4).

\section{Discussion}

Lymph nodes are often encountered in childhood. In a study conducted with children under the age of five, lymph nodes were found in $44 \%$ of healthy children and in $64 \%$ of the children examined for a disease. ${ }^{[6]}$ In order for the palpated lymph node to be considered pathological, its size should be above normal limits and/or its structure should be deteriorated. In a significant portion of our cases (i.e., $24.6 \%)$, lymph nodes were not evaluated as LAP, the reason for referring to oncology could not be explained and these cases were not followed up.

Most of the enlargements in lymph nodes are reactive, have a benign course, and usually develop during viral infections. Since childhood cancers are considered in its etiology, the growth of lymph nodes worries families and even doctors, regardless of their size and structure. These concerns may cause patients to be referred to oncology without being adequately evaluated and monitored. The possibility of malignancy is low, especially in LAPs, present for less than 2-4 weeks or have not increased in size for more than a year. Cancerous tumor development is also less frequently seen in mobile, soft LAPs less than $2.5-3 \mathrm{~cm}$ in size, in the patients with cervical location, and without concomitant severe systemic signs and symptoms. ${ }^{[1-10]}$

Patients should be adequately evaluated for these features and oncology consultation should be requested in case of doubt. In our study, only three patients (2\%) had extensive lymph node involvement and $85.5 \%$ of the regional lymph nodes were located in the cervical or submandibular regions. Only $6.7 \%$ of thepatients had lymph nodes measuring $>2.5$ $\mathrm{cm}$ in diameter. Sixty percent of patients had signs of upper respiratory tract infection at the time of diagnosis or previously. The time elapsed between noticing the lymph node and referral of the patient to us was less than two weeks in $61 \%$ and more than one year in $12 \%$ of the cases.

Table 4. Characteristics of the patients diagnosed as Hodgkin lymphoma

\begin{tabular}{lcccccc}
\hline Patient & Age (years) & Duration (mos) & Region & Size (cm) & Systemic findings & Chest X-ray \\
\hline 1 & 4 & 1 & Cervical & 4 & None & Normal \\
2 & 15 & 2 & Cervical & 2.5 & Pruritus & Mediastinal LAP \\
3 & 15 & 3 & Supraclavicular & 4 & Weight loss, sweating, a fever & Mediastinal LAP \\
4 & 12 & 6 & Supraclavicular and axillary & 4 & None & Mediastinal LAP \\
\hline
\end{tabular}


In particular, patients with a disease history of more than one year had suffered recurrent episodes of infection, and a significant proportion was accompanied by allergic rhinitis and/or adenoid face. Although the size of the lymph node regressed after the infection was resolved, it was observed that the families were worried because the lymph nodes did not disappear completely. An important health problem that was overlooked was dental caries and none of the patients with dental caries were directed to dentistry. However, a patient in the active period of chickenpox infection was sent to the oncology outpatient clinic where patients with impaired immune system were monitored. These data suggested that patients were not adequately evaluated for risk of cancer before they were referred to oncology.

It was noteworthy that all of our patients had undergone recurrent US examinations directed their affected lymph node. All cases were followed up with US and referred to oncology even in the presence of millimetric increases in lymph node size. LAP size was specified in most of these USs, and sufficient information about the lymph node structure was not provided. Similar to a study in our country, ${ }^{[11]}$ the dimensions stated in the US report were smaller than cases palpated during examination. Although US is not routinely recommended for the diagnosis and followup of LAPs, most of which are reactive, and frequently ultrasonographic examinations were performed in studies conducted in our country with reported rates ranging between 50 and $70 \% \cdot{ }^{[1-13]}$ Requesting US in primary care without adequate clinical evaluation of the patients and inadequate radiological evaluations may lead to unnecessary referral of the patients to oncology.

Biopsy and subsequent histopathological examination are the last steps in revealing the LAP etiology..$^{[1-3]}$ The rate of the patients diagnosed with cancer based on biopsy results varies according to age and the center where these patients are followed up. The prevalence of malignancy is low in primary health care centers, especially in children. In reference centers, the rates are higher in patients whose clinical findings suggest malignancy. ${ }^{[13]}$ In studies conducted in children of our country, the cancer rate has been reported in a wide range, such as $1-38 \%{ }^{[14-21]}$ Incidence rates of cancer reported from pediatric oncology outpatient clinics range most prevalently between 1 , and 38 percent. ${ }^{[14-21]}$ The highest rates $(>15 \%)$ have been generally reported in studies conducted in pediatric oncology polyclinics. ${ }^{[14-21]}$ In a study reporting only the results of patients undergoing biopsy, the rate of cancer reportedly increased up to $40.8 \%$. $^{[22]}$

In a study in our country, contrary to what is expected, only one of 98 patients who were sent to the pediatric oncology center was diagnosed with Hodgkin lymphoma. ${ }^{[11]} \mathrm{Al}-$ though our study was conducted in the oncology outpatient clinic, only $3 \%$ of the cases received the diagnosis of cancer which is very low for a reference center. That other studies were usually conducted in university hospitals may have caused this difference. Our center is a public hospital and access to our oncology clinic is easier than university hospitals. We think that the malignancy rate is low because the low-risk patients who were not clinically evaluated in the primary care applied to our outpatient clinic.

Hodgkin lymphoma is the most common childhood malignancy diagnosed based on histopathological examinations of peripheral lymph node biopsy specimens. Four of our patients were diagnosed as Hodgkin lymphoma as a result of histopathological examination. All of these patients had one or more features that increased the risk of cancer, such as long disease history, supraclavicular location, more than 2.5 $\mathrm{cm}$ growth in size, and concomitant systemic findings. Since the number of patients with cancer is very small, the relationship between the clinical and laboratory features of the patients and malignancy could not be evaluated statistically.

\section{Conclusion}

In conclusion, only $3 \%$ of our patients were diagnosed with pediatric cancer. This rate is quite low for an oncology center. It was observed that patients who could be followed in primary health care centers were referred to the oncology outpatient clinic. Better clinical evaluation and monitoring of patients as for location, growth, structural alterations in lymph nodes, and/or additional systemic signs and symptoms will reduce unnecessary referrals.

\section{Disclosures}

Peer-review: Externally peer-reviewed.

Conflict of Interest: None declared.

Authorship Contributions: Concept - S.V.; Design - S.V., D.B.G.; Supervision - S.V., D.B.G.; Materials - S.V., E.C.; Data collection \&/or processing - S.V., E.C.; Analysis and/or interpretation - S.V., D.B.G.; Literature search - S.V.; Writing - S.V.; Critical review - D.B.G.

\section{References}

1. Kilburn LB, Malogolowkin MH, Quinn JJ, Siegel SS, Steuber CP. Clinical Assesment and differantial diagnosis of the child with suspected cancer. In: Pizzo PA, Poplac DG, David G, editors. Principles and Practice of Pediatric Oncology. 7th ed.Philadelphia: Lippincott Williams \&Wilkins; 2015. p. 101-12.

2. Lanskowsky P. Lymphadenopathy and Diseases of the Spleen. In: Lanskowsky P, editor. Lanzkowsky's Manual of Pediatric Hematology and Oncology. 5th ed. NewYork: Elsevier; 2011. p. 461-71.

3. Niedzielska G, Kotowski M, Niedzielski A, Dybiec E, Wieczorek P. Cervical lymphadenopathy in children-incidence and diagnostic 
management. Int J Pediatr Otorhinolaryngol 2007;71:51-6.

4. Friedmann AM. Evaluation and management of lymphadenopathy in children. Pediatr Rev 2008;29:53-60. [CrossRef]

5. Bazemore AW, Smucker DR. Lymphadenopathy and malignancy. Am Fam Physician 2002;66:2103-10.

6. Herzog LW. Prevalence of lymphadenopathy of the head and neck in infants and children. Clin Pediatr (Phila) 1983;22:485-7.

7. Fragkandrea I, Nixon JA, Panagopoulou P. Signs and symptoms of childhood cancer: a guide for early recognition. Am Fam Physician 2013;88:185-92.

8. Locke R, Comfort R, Kubba H. When does an enlarged cervical lymph node in a child need excision? A systematic review. Int J Pediatr Otorhinolaryngol 2014;78:393-401. [CrossRef]

9. Farndon S, Behjati S, Jonas N, Messahel B. How to use... lymph node biopsy in paediatrics. Arch Dis Child Educ Pract Ed 2017;102:244-8. [CrossRef]

10. Meier JD, Grimmer JF. Evaluation and management of neck masses in children. Am Fam Physician 2014;89:353-8.

11. Ataş E, Kesik V, Fidancı MK, Kısmet E, KöseoğluV. Evaluation of children with lympadenopathy. Turk Pediatri Ars 2014;49:30-5.

12. Bozlak S, Varkal MA, Yildiz I, Toprak S, Karaman S, Erol OB, et al. Cervical lymphadenopathies in children: A prospective clinical cohort study. Int J Pediatr Otorhinolaryngol 2016;82:81-7. [CrossRef]

13. Sarsu SB, Sahin K. A retrospective evaluation of lymphadenopathy in children in a single center's experience. J Pak Med Assoc 2016;66:654-7.
14. Karaman A, Karaman I, Cavuşoğlu YH, Erdoğan D. The ongoing problem with peripheral lymphadenopathies: which ones are malignant?. Pediatr Surg Int 2010;26:247-50.

15. Aykaç K, Özsürekci Y, Başaranoğlu ST, Öncel EK, Cengiz AB, Kara A, et al. Çocuklarda lenfadenopati nedenleri: Hacettepe Üniversitesi enfeksiyon hastalıkları deneyimi 2015-2016. Çocuk Sağlığı ve Hastalıkları Dergisi 2016;59:155-60.

16. Özkale Y, Özkale M, Sipah T. Peripheral Lymphadenopathy in Childhood: Single Center Study. Cukurova Medical Journal 2015;40:418-29. [CrossRef]

17. Kumral A, Olgun N, Uysal KM, Corapcioğlu F, Oren H, Sarialioğlu F. Assessment of peripheral lymphadenopathies: experience at a pediatric hematology-oncology department in Turkey. Pediatr Hematol Oncol 2002;19:211-8. [CrossRef]

18. Karadeniz C, Oguz A, Ezer U, Oztürk G, Dursun A. The etiology of peripheral lymphadenopathy in children. Pediatr Hematol Oncol 1999;16:525-31. [CrossRef]

19. Yaris N, Cakir M, Sözen E, Cobanoglu U. Analysis of children with peripheral lymphadenopathy. Clin Pediatr (Phila) 2006;45:544-9.

20. Oguz A, Karadeniz C, Temel EA, Citak EC, Okur FV. Evaluation of peripheral lymphadenopathy in children. Pediatr Hematol Oncol 2006;23:549-61. [CrossRef]

21. Celenk F, Baysal E, Aytac I, Durucu C, Sari I, Mumbuc S, et al. Incidence and predictors of malignancy in children with persistent cervical lymphadenopathy. Int J Pediatr Otorhinolaryngol 2013;77:2004-7. [CrossRef] 